\section{Weiter- und Fortbildungskurse in Ungarn}

Auch im Jahr 2017 werden im bekannten Kurszentrum in Csòlyospàlos in der schönen Puszta zahlreiche SGUM-anerkannte Sonografie-Kurse für Anfänger und Fortgeschrittene durchgeführt. Aus aktuellem Grund werden zwei identische spezielle Tarmed-Einführungskurse im Dezember ausgeschrieben, welche auch für MPA's oder andere Interessenten offen sind.
Nach wie vor werden auch Kursleiter mit eigenen Programmen gesucht, für welche die gesamte Infrastruktur angeboten werden kann.

Einzelheiten unter www.ungarnkurse.ch

Die ursprüngliche Liste wurde bereits im Heft 2-2017 publiziert.
Weitere Kurse sind noch geplant, Einzelheiten folgen auf der Webseite.

Das Kursprogramm 2018 wird ab ca. Juni 2017 aufgeschaltet sein.

Das gesamte Angebot und die Einzelheiten zu den Kursen sind auch unter www. ungarnkurse.ch im Internet aufgeschaltet.

- Zusätzliche neue Kurse im Jahr 2017

\begin{tabular}{|c|c|c|}
\hline Datum & Kursbezeichnung & Kursleiter \\
\hline $\begin{array}{l}\text { Do } 14.12 .- \\
\text { Sa } 16.12 .2017 \\
\text { (Kurs 206) }\end{array}$ & $\begin{array}{l}\text { Spezialkurs Abrechnung und Tarmed-Einführung 1/2017 } \\
\text { Einführung zur Tarmed-Version 1.09 BR } \\
\text { Mit Begleitprogramm }\end{array}$ & Dr. Beat Dubs \\
\hline $\begin{array}{l}\text { Do } 28.12 .- \\
\text { Sa } 30.12 .2017 \\
\text { (Kurs 207) }\end{array}$ & $\begin{array}{l}\text { Spezialkurs Abrechnung und Tarmed-Einführung 2/2017 } \\
\text { Einführung zur Tarmed-Version 1.09 BR } \\
\text { Mit Begleitprogramm }\end{array}$ & Dr. Beat Dubs \\
\hline
\end{tabular}

